\begin{tabular}{|c|c|}
\hline $\begin{array}{l}\text { Journal of } \\
\text { Radiotherapy } \\
\text { in Practice }\end{array}$ & $\begin{array}{l}\text { Yournal of Radiotherapy in Practice (2010) } \\
\text { 9, 265-265 } \\
\text { ๑ Cambrige University Press } 2010 \\
\text { doi:10.1017/S1460396910000336 }\end{array}$ \\
\hline
\end{tabular}

\title{
Letter
}

\section{Research participation among clinical oncology trainees in the Middle East and North Africa}

\author{
Ahmed Salem, Sameh Hashem, Layth Y.I. Mula-Hussain, Imad Jaradat, Jamal Khader, Abdelatif Almousa \\ Department of Radiation Oncology, King Hussein Cancer Center, Amman, Fordan
}

Middle Eastern and North African (MENA) clinical oncology physicians spend 10 years on average - from the dawn of medical school to the conclusion of clinical training. Amidst this enduring journey, residents and fellows spare little time for research projects ensuring low ratio of trainees with peer-reviewed publications at the time of graduation.

Elucidation of "research virginity" among MENA clinical oncology trainees is two-fold. First, trainees are preoccupied by the stresses, mind-boggling academic demands and overwhelming fund of effort necessary to satisfy program requirements for graduation. Second, trainees hold firm certitude that the rigorous and stringent review process will often impede publication of their work. Although an exhaustive peer review is undeniably crucial to the advancement of medical research, it can - at times - be counter-productive towards the participation of junior MENA clinical oncology physicians in the research field.

So far, rewarding research accomplishments during early stages of training are attained through windows of full-time dedication via research fellowships or clinical fellowships with pre-set research allocation. Disappointingly, such positions are consistently limited by scope and availability. Moreover, most clinical fellowships do not adequately address the issue of research participation. As such, thousands of

Correspondence to: Abdelatif Almousa, Department of Radiation Oncology, King Hussein Cancer Center, Amman, Jordan. Email: aalmousa@khcc.jo
MENA clinical oncology graduates are ordinarily concluding clinical training with little if any research exposure.

Clearly, involvement of junior MENA physicians in research projects is neither imperative nor cardinal to the future of medicine. Nonetheless, premier participation implies continued research activity throughout the upcoming career. Currently, the level of participation relies mainly upon trainee initiative and enthusiasm. Encouragement and appraise by professors, staff physicians and program directors frequently arrives short from achieving universal participation. This holds true in the residency and fellowship stages.

Tackling the poor level of research participation among clinical oncology trainees is difficult. At one level, it is essential to re-evaluate the work load and academic pressure during medical training in an attempt to establish strategies for encouraging fruitful research participation among trainees. Similarly, frameworks advocating active research participation at an early stage of clinical oncology training have to be further reviewed. More importantly, however, MENA medical journals are compelled to lay foundation for applauding young researchers by allocating journal space and at times - invited editorials devoted to the promotion of active research participation at early stages of the medical career. 